\title{
A IMPOSSIBILIDADE DE ESCOLHA DO REGIME DE BENS PARA MAIORES DE 70 ANOS
}

\section{THE IMPOSSIBILITY OF CHOOSING THE PROPERTY REGIME FOR PEOPLE OVER 70 YEARS OLD}

\author{
Washington Luiz Ferreira Dias Lopes*
}

\begin{abstract}
RESUMO
O direito do idoso é tema relevante a ser abordado no direito brasileiro nos dias de hoje, afinal, temos uma população de mais de 14 milhões de idosos em um país cuja expectativa de vida cresce a cada ano. Envelhecer é uma etapa importante da vida, e pode se revelar como um momento final da vivência ou como uma fase em que se conquista experiências e se desfruta da maturidade. Tamanha é a importância do papel do idoso em nossa sociedade que seus direitos são resguardados pela Constituição Federal e reafirmados no Estatuto do Idoso. Diante disso, analisar o tratamento dado ao idoso no instituto do casamento no direito de família é a problemática que envolve a presente pesquisa, posto que ele não pode optar pelo regime de bens que julgar conveniente.
\end{abstract}

Palavras-chave: Idoso. Casamento. Regime de bens.

\begin{abstract}
The right of the elderly is undoubtedly one of the most important issues to be addressed in Brazilian law these days, after all, having a population of over 14 million elderly people in a country whose life expectancy is growing every year. Aging is an important stage of life, and may prove as a final moment of experience or as a phase to enjoy achievements to came with maturity. Such is the importance of the elderly's role in our society that their rights are safeguarded by the Constitution and reaffirmed in Statute of the Elderly. Therefore, examine the treatment of the elderly in wedding institute in family law is the problem addressed the present study, since it cannot choose the property regime it deems appropriate.
\end{abstract}

Keywords: Elderly. Wedding. Property regime

\section{INTRODUÇÃO}

Nas últimas décadas, o Brasil tem registrado um aumento no número de idosos em sua população. De acordo com o Censo de 2017 realizado pelo Instituto Brasileiro de Geografia e Estatística (IBGE), são pouco mais de 28 milhões de pessoas com mais de 60 anos no país e a expectativa é de que este número aumente ainda mais ao longo dos próximos anos (IBGE, 2020).

O processo de envelhecimento tem sido considerado historicamente por meio de duas fortes e opostas perspectivas: uma que reconhece como a etapa final da vida, a fase de declínio que culmina na morte e outra que concebe como a fase da maturidade e da serenidade

Artigo submetido em 23 de fevereiro de 2021 e aprovado em 26 de janeiro de 2022.

*Mestrando em Direito pela UFOP. E-mail: washington.diaslopes@ @otmail.com. 
(OLIVEIRA; PASIAN, e JACQUEMIN, 2001). A primeira ideia encontra-se difundida na população de um modo geral. Conforme Rolla (1991), um envelhecer positivo fortalece o sentimento de identidade, sem necessariamente envolver tanta deterioração psíquica quanto comumente se associa a essa fase.

A Constituição Federal de 1988 refletindo os anseios e as mudanças já ocorrentes na sociedade deu uma nova configuração à família, ramo do Direito Civil que mais passou por transformações nos últimos tempos, passando a legitimar, por exemplo, as uniões estáveis. Além disso, no intuito de proteger os interesses de cada pessoa humana, principalmente dos mais vulneráveis, imputou-se à família, à sociedade e ao Estado o dever de assegurá-lo. (BRASIL, 1988).

Apesar da Lei Maior garantir que as pessoas idosas têm assegurada a sua participação e bem-estar na comunidade, é inegável que a mera normatização de direitos não significa seu implemento, visto que estes direitos nunca foram garantidos de forma efetiva, levando à criação, em 2003, do Estatuto do Idoso. Contudo, antes da vigência desta lei, o Código Civil pátrio já atribuía uma condição "especial" aos idosos, impondo-lhes a obrigatoriedade do regime da separação de bens no casamento.

A partir dessa problemática a presente pesquisa visa uma análise acerca do idoso e seu tratamento no direito de família no que tange ao casamento, posto que ele não pode optar pelo regime de bens que julgar conveniente para a união. Desse modo, a liberdade e a autonomia dos maiores de 70 anos, direitos fundamentais garantidos pela Constituição, não são levados em consideração pelo legislador ou são considerados de tal forma que essa superproteção pode ter caracterizado uma limitação à autonomia desses indivíduos.

É inegável que a expectativa de vida das pessoas aumentou com o passar do tempo. O idoso deve ter sua importância reconhecida na sociedade como aquele que muito contribuiu. Portanto, é importante ter um olhar mais atento a esta etapa da vida que nem sempre será sinônimo de vulnerabilidade, mas sim de experiência e respeito. A autonomia do idoso deve ser respeitada e a sua limitação deve ser criteriosamente analisada no caso concreto com as ferramentas já existentes em nosso sistema jurídico.

A estrutura do presente trabalho se inicia apresentando o que é idoso dentro do contexto do Direito Civil brasileiro no tocante ao casamento. Após, é realizada uma análise crítica do instituto do casamento e do regime da separação de bens. Adiante, analisa-se a questão do casamento do idoso no direito civil brasileiro e, após a apresentação da metodologia, apresentase a conclusão da pesquisa, em que se percebe que há uma discriminação travestida de excesso de proteção e, por consequência, uma inconstitucionalidade, na proibição da escolha do regime de bens no casamento de maiores de setenta anos.

\section{DO IDOSO E DO PROCESSO DE ENVELHECIMENTO}

Envelhecer é um processo inerente à vida humana. Tradicionalmente, era comum relacionar o termo idoso apenas aos nossos avós ou àquelas pessoas que viviam em asilos ou casas de repouso. A impressão é que aquela figura afetuosa de cabelos brancos sempre carregara aquela aparência frágil, tão reforçada, principalmente pela literatura romântica.

De acordo com a Organização Pan-Americana de Saúde (2005), o envelhecimento consiste num "processo sequencial, individual, acumulativo, irreversível, universal, não patológico, de deterioração de um organismo maduro, próprio a todos os membros da sociedade. Porém, cumpre destacar que essa deterioração não está inerentemente atrelada à perde de percepção da realidade ou à queda da salubridade mental. Envelhecer é um processo que faz parte da vida, mas que só deve ser encarado como sinônimo de definhamento negativo do indivíduo quando há a constatação de eventuais patologias. 
Nesse contexto, tem-se, portanto, que o idoso é assim compreendido por um critério técnico e não aparente, sendo considerado pelo Estatuto do Idoso, lei 10.741 de 01 outubro de 2003, aqueles com idade igual ou superior a 60 anos.

Conforme destaca os dizeres da Política Nacional de Saúde da Pessoa Idosa (2006), a população brasileira, nos últimos 60 anos não só está envelhecendo, como também é composta por uma espécie de proporção "mais idosa", aqueles considerados com idade a partir de 80 anos, ou seja, a própria população idosa também está envelhecendo dentro do seu nicho de existência. $\mathrm{O}$ interessante nessa questão é que nesses grupos existem pessoas em pleno vigor físico e mental e outras em uma situação de maior ou menor vulnerabilidade, o que apenas reforça, portanto, o entendimento de que a higidez mental de um idoso não é medida pelo avanço da idade, mas sim pelas circunstâncias do caso concreto.

\section{O IDOSO E O CASAMENTO}

A ideia mais primitiva que se tem de casamento remonta ao Direito Romano. Conforme leciona Pereira (2016, p. 79), o instituto trazia antes a compreensão mais de uma relação jurídica do que uma celebração em si, já que o que era levado em consideração era a situação de convivência no plano fático, observando-se a manifestação de vontade dos nubentes. Tempos depois, o cristianismo, eleva o casamento ao patamar de sacramento que une o homem e a mulher numa só carne e comunhão de vida indissolúvel.

A partir dessa afirmação percebe-se que, naquela época, o casamento como uma espécie de sociedade entre o homem e a mulher, e, sendo uma sociedade ou espécie de contrato, já trabalhava a ideia de regime de bens que em vigor atualmente.

De acordo com José Cretella Júnior (1980, p. 118), havia, entretanto, duas espécies de casamentos: o casamento сит тапи е о sine manu, sendo o primeiro designado como um casamento em que a mulher fica sob o poder do marido ou do pater familias do marido, caso este seja "alieni júris"; o segundo, por sua vez, designa um casamento em que a mulher não cai sobre o poder do marido, continuando sob a "manus" do pater da família de que provém.

Com a evolução do instituto tem-se, no Brasil, atualmente, uma garantia de igualdade entre as partes no casamento, podendo os cônjuges disporem sobre o patrimônio constituído em decorrência da união da maneira que preferirem quando da escolha do regime de bens que irá reger a união. É o que afirma Carvalho (1996, p.21), quando reforça que a Constituição Federal de 1988 perfilha sobre o direito de igualdade entre o homem e a mulher no casamento, igualdade essa percebida no regime de bens, máxime no que tange a administração do patrimônio conjugal.

Logo, ainda de acordo com Carvalho (1996), com a evolução histórico-social do casamento, este tipo de contrato até então inabalável, que sempre nos remete(ia) à famosa frase "até que a morte os separe", passou a ter menor estabilidade com o surgimento do divórcio, obrigando o legislador a mudar a lei de modo que os valores tradicionais da família (isso no Brasil, que é um país tradicionalmente católico) foram cedendo espaço aos sentimentos pessoais - a vontade, por assim dizer, como inclusive era na época romana de surgimento do instituto, não se limitando a ser uma união ou construção de patrimônio.

O legislador passou a levar em consideração, a partir dessa mudança de perfil da sociedade, no tocante ao aspecto patrimonial, apenas o que o casal amealhou desde o casamento, para efeitos de partilha, em não havendo regime expressamente escolhido pelos nubentes.

A vida, a dignidade, a liberdade e a autonomia são preceitos assegurados constitucionalmente e ligam-se intimamente à pessoa humana, caracterizando-a como sujeito de direitos. Tais preceitos, porém, entram em choque quando são discutidos os limites deles nos casos concretos. $\mathrm{O}$ instituto do casamento está intimamente ligado ao exercício desses direitos 
na medida em que se caracteriza por ser uma clara demonstração de autonomia da vontade do indivíduo.

Nesse contexto, a polêmica ora discutida está ligada ao fato de o Estado, que é um garantidor dos direitos fundamentais, optar por intervir e limitá-los, impondo aos maiores de 70 anos o regime de separação de bens no casamento, como se nota no artigo 1.640 do Código Civil sem seu inciso II, não levando em consideração que nem todo idoso tem discernimento reduzido, sendo, portanto, plenamente capaz de escolher o regime em que quer se casar e de ser capaz de realizar planejamento familiar.

\section{DO REGIME DE BENS}

As relações patrimoniais em Direito de Família são alvo de infindáveis discussões. A temática do regime de bens sempre desponta principalmente quando se trata do instituto do casamento, tendo em vista que o Código Civil vigente prevê, na questão do direito patrimonial, algumas espécies de regime de bens que podem, preenchidos os requisitos, ser escolhidas pelos nubentes.

Caio Mário da Silva Pereira (2016, p. 217), ensina que "os regimes de bens constituem, pois, os princípios jurídicos que disciplinam as relações econômicas entre cônjuges, na constância do matrimônio". Dessa forma, entende-se que o regime de bens se institui pela vontade dos nubentes, ou da lei, não sendo mais do que um contrato celebrado entre ambos dentro dos modelos legais.

Nesse contexto, tendo em vista a temática da presente pesquisa, apenas o regime da separação de bens será observado, posto que, de todas as espécies compreendidas pela lei civil, esta é a única que é imposta ao casamento do maior de 70 anos.

\subsection{O regime de separação de bens e o casamento do idoso}

Para compreender a situação daqueles que desejam se casar e possuem idade superior a setenta anos, é importante analisarmos a situação peculiar a partir do entendimento crítico do regime imposto, qual seja, o da separação de bens.

Conforme Ferriani (2012), o regime da separação de bens importa na incomunicabilidade dos bens que cada um possuía ao se casar e dos bens que se adquirem na constância do casamento. Há, portanto, dois patrimônios distintos: o do marido e o da mulher. Não só o ativo de cada um é separado, como também o passivo (dívidas).

Maria Helena Diniz (2015), reforça destacando que:

O regime da separação de bens $(\mathrm{CC}$, art. 1.687) vem a ser aquele que cada consorte conserva, com exclusividade, o domínio, posse e administração de seus bens presentes e futuros e a responsabilidade pelos débitos anteriores e posteriores ao matrimônio. Portanto, existem dois patrimônios perfeitamente separados e distintos: o do marido e o da mulher. (DINIZ, 2015, p. 206).

De acordo com o Código Civil de 2002, em vigor

Art. 1.687. Estipulada a separação de bens, estes permanecerão sob a administração exclusiva de cada um dos cônjuges, que os poderá livremente alienar ou gravar de ônus real.

Art. 1.688. Ambos os cônjuges são obrigados a contribuir para as despesas do casal na proporção dos rendimentos de seu trabalho e de seus bens, salvo estipulação em contrário no pacto antenupcial (BRASIL, 2002). 
Portanto, cada consorte, nesse tipo de regime de bens, deve contribuir da maneira que for possível para com o patrimônio do casal, na medida proporcional aos seus respectivos rendimentos.

Diante disso, é compreensível afirmar que há uma inconstitucionalidade na imposição da obrigação de se casar no regime de separação de bens ao idoso, posto que referida inconstitucionalidade reside no fato de que a sua liberdade está limitada, tendo em vista que existe uma discriminação simplesmente pela idade, o que é condenado pela própria Constituição Federal, vez que esta afirma em seu artigo terceiro, inciso quarto, que um dos "objetivos fundamentais da República Federativa do Brasil" é "promover o bem de todos, sem preconceitos de origem, raça, sexo, cor, idade e quaisquer outras formas de discriminação. (BRASIL, 1988, grifo nosso).

Nesse sentido, afirma Zeno Veloso (2017):

Outro problema a ser resolvido, é a respeito da inconstitucionalidade do inciso II, do art. 1.641, do Código Civil, que fala do casamento do idoso (pessoa com 70 anos de idade), que fica submetido ao regime da separação obrigatória, opinando-se que isso representa o reconhecimento de uma 'semi capacidade' do nubente que, por causa da idade avançada, não tem possibilidade de escolher, livremente o regime de bens de seu casamento. (VELOSO, 2017).

Quanto ao argumento de que tal regime visa tão somente a proteção ao idoso e ao seu patrimônio contra pessoas de má-fé que, por ventura, venham a se relacionar com este, não procede pelo simples fato de que existem outras maneiras de o idoso beneficiar o seu cônjuge, transferindo-lhe seu patrimônio, por exemplo, por meio do testamento.

A imposição de tal regime, além disso, põe em dúvida a capacidade de discernimento da pessoa idosa, o que se configura também, como mais uma forma preconceituosa de enxergar o idoso na sociedade.

A presunção de desorganização mental das pessoas com mais de 70 anos é absolutamente descabida. É preconceituosa. A associação da velhice à debilidade intelectual é equivocada e não pode ser presumida de forma absoluta, como prescreve a lei. Ninguém se torna incapaz exclusivamente por causa da idade avançada. Casamentos por interesses patrimoniais podem existir em todas as idades. Deslumbramentos e paixões descontroladas podem atingir a todos. Porém, a vulnerabilidade emocional decorre muito mais do temperamento, da personalidade $\mathrm{e}$ da história de vida da pessoa do que propriamente da idade. Por isso, o Código Civil precisa ser modificado quanto a esse aspecto. (FERRIANI, 2012).

É importante compreender que o casamento sobretudo, é um ato de vontade e seus correlacionados, como o regime de bens, também deve estar atrelado a essa demonstração de vontade e não a imposição estatal. Parece discrepante o fato de se reconhecer que o indivíduo seja capaz e livre para se relacionar e realizar um planejamento familiar, podendo inclusive ter filhos, mas ser impedido, em razão da idade, de escolher o regime de bens do casamento que melhor lhe aprouver.

No Direito brasileiro, após mais de duas décadas de ditadura sob o regime militar, a Constituição democrática de 1988 (BRASIL, 1988) explicitou, no art. $1^{\circ}$, III, a dignidade da pessoa humana como um dos fundamentos da república. A dignidade humana, então, não é criação da ordem constitucional, embora seja por ela respeitada e protegida. A Constituição consagrou o princípio e, considerando a sua eminência, proclamou-o entre os princípios fundamentais, atribuindo-lhe o valor supremo de alicerce da ordem jurídica democrática. ${ }^{1} \mathrm{~A}$

\footnotetext{
${ }^{1}$ Esta idéia é explorada na obra de G. TEPEDINO, que tem parte substanciosa reunida em seu Temas de Direito
} Civil, já citado, com especial relevo nos primeiros trabalhos que a compõem: Premissas metodológicas para a 
integridade da pessoa humana, pode-se afirmar, sempre foi objeto de preocupação do direito, embora nem sempre sob a mesma perspectiva. (DINIZ, 2011).

O fundamento jurídico da dignidade humana manifesta-se, em primeiro lugar, no princípio da igualdade, isto é, no direito de não receber qualquer tratamento discriminatório, no direito de ter direitos iguais aos de todos os demais. Esta é uma das formas de igualdade, a primeira porque a mais básica, a que normalmente se denomina de "igualdade formal", segundo a qual "todos são iguais perante a lei" (MORAES, 2006, p.18).

No Brasil, o idoso, parte da população que, segundo o IBGE vem aumentando a cada ano, é amparada pelo o Estatuto do Idoso, resultado da preocupação em desenvolver cuidados especiais a esta parte mais vulnerável da sociedade. Considera-se, com efeito, conforme Chauí (1997), que a humanidade das pessoas reside no fato de serem elas, racionais, dotadas de livrearbítrio e de capacidade.

De acordo com Fernanda de Paula Diniz:

\begin{abstract}
No Brasil, especificamente, são criadas inúmeras leis com o intuito de defender essa classe de indivíduos. Todavia, os brasileiros em sua maioria não têm conhecimento de todos os instrumentos de proteção, o que acaba por torná-los, na grande parte das vezes, obsoletos. Aliada à questão do desconhecimento da lei, por mais contraditório que pareça ser, outro problema é a limitação ao exercício dos direitos dos idosos que muitas delas acarretam. Em alguns diplomas, ao invés de sujeitos de direitos, os idosos passam a ser apenas objeto de proteção, alijados de muitos dos seus direitos fundamentais (DINIZ, 2011, p.2).
\end{abstract}

O Código Civil em vigor possui dispositivos que, na tentativa de uma proteção, oferecem uma superproteção ao idoso, chegando a violar os direitos fundamentais que estão consagrados na Constituição, como o art. 1.641 que impõe o regime de separação obrigatória de bens aos maiores de 70 (setenta) anos, revelando um desrespeito ao direito de liberdade de escolha (BRASIL, 2002).

É importante ressaltar que a redação original do referido artigo considerava idoso e estabelecia a obrigatoriedade de contrair matrimônio sob o regime da separação obrigatória os maiores de 60 (sessenta) anos. Tal artigo foi alterado pela Lei 12.344 de nove de setembro de 2010, que alterou a idade de 60 (sessenta) para 70 (setenta) anos (BRASIL, 2010).

De acordo com Ferriani (2012), O Código Civil revogado, de 1916, por sua vez, imprimia a mesma restrição aos homens com mais de 60 anos e às mulheres com mais de 50 anos. Clóvis Beviláqua justificou a regra partindo da premissa segundo a qual pessoas mais velhas podem ser vítimas de casamentos interesseiros.

No mesmo sentido tramitam na Câmara dos Deputados e no Senado Federal, diversos outros projetos de lei sob o mesmo enfoque, entre eles o Projeto de lei ${ }^{\circ} 4.944 / 2009$ do Deputado Osório Adriano, o qual visa alterar o dispositivo para 80 anos de idade e a PL2285/2007, do Deputado Sergio Barradas que propõe a revogação completa do atual artigo 1.641 do Código Civil de 2002. Ambos demonstram insatisfação em relação à imposição existente. (LUCAS; OLIVEIRA. 2014).

Além disso, existe um projeto de Lei (PLS 760/2015), de autoria do senador Davi Alcolumbre que tem o objetivo de revogar a proibição aqui discutida, tendo em vista que houve um aumento na qualidade de vida do brasileiro e, consequentemente na expectativa de vida, de

constitucionalização do Direito Civil (p. 1-22). A tutela de personalidade no ordenamento civil-constitucional brasileiro (p. 23-58) e Direitos Humanos e relações jurídicas privadas (p. 59-78). 
modo que o maior de 70 anos possui, na visão do senador, discernimento necessário para escolher o regime de bens que desejar. (SENADO FEDERAL, 2015).

Dessa maneira, não há motivos que justifiquem a aplicação deste regime aos idosos atualmente, pois nossa sociedade está em constante evolução, tal imposição só possuía eficácia naquele contexto social. (LUCAS; OLIVEIRA. 2014).

Convém lembrar que neste ambiente, de acordo com Moraes (2006), a vulnerabilidade humana será tutelada, prioritariamente, onde quer que ela se manifeste, de modo que terão precedência os direitos e as prerrogativas de determinados grupos considerados, de uma maneira ou de outra frágeis e que estão a exigir, por conseguinte, a especial proteção da lei, como os idosos, as crianças e os portadores de deficiência.

Conforme Fernanda de Paula Diniz (2011), apesar de o legislador possuir objetivos nobres ao estabelecer medidas de proteção aos idosos, os quais, juntamente com as crianças e adolescentes que, em tese seriam mais frágeis que os adultos, tais medidas não devem ser empecilho à sua participação nas relações jurídicas como sujeitos que são. Portanto, se o idoso apresenta condição tanto física quanto psíquica de fazer a escolha que é melhor para si, deve ter o direito de exercê-la.

\begin{abstract}
No princípio de proteção à integridade psicofísica da pessoa humana estão contemplados, tradicionalmente, apenas o direito de não ser torturado e o de ser titular de certas garantias penais, como o tratamento do preso nas detenções e nos interrogatórios, a proibição de penas cruéis, etc. na esfera cível, no entanto, a integridade psicofísica, vem servindo a garantir numerosos direitos da personalidade (vida, nome, imagem, honra, privacidade, corpo, identidade pessoal), instituindo hoje, o que se poderia entender como um amplíssimo "direito à saúde", compreendida esta como completo bem-estar social. ${ }^{2}$ No princípio está contido ainda, e principalmente, o direito à existência digna, tendo sido previsto pelo texto constitucional (MORAES, 2006, p.28).
\end{abstract}

No mesmo sentido caminha Maria Helena Diniz (2015), quando explica que:

\begin{abstract}
Se impõe, por lei, o regime da separação de bens para evitar que o casamento se dê por interesse econômico. [...], Mas não se pode olvidar que o nubente, que sofre tal capitis diminutis imposta pelo Estado, tem maturidade suficiente para tomar uma decisão relativamente aos seus bens e é plenamente capaz de exercer atos na vida civil. Logo, parece-nos que, juridicamente, não teria sentido essa restrição legal em função de idade avançada do nubente, salvo o fato de se tornar mais vulnerável psicóloga ou emocionalmente, podendo, por isso, ser alvo fácil do famoso chamado "golpe do baú". (DINIZ, 2015, p. 208).
\end{abstract}

Vale ressaltar que há um entendimento por parte de doutrinadores civilistas de que a Súmula 377 pode ser afastada pelos nubentes na medida em que trata de matéria afeita à disponibilidade de direitos, ou seja, os consortes pode alterar a maneira como o regime imposto será tratado no casamento, alterando seus efeitos, optando por uma separação absoluta de bens, por exemplo ao mesmo tempo em que não deixa de observar a norma de ordem pública que o Código Civil impõe quando adota um regime de bens específico para maiores de setenta anos, e isso é um verdadeiro exercício de autonomia privada. (ALVES, 2017).

\title{
5 CONSIDERAÇÕES FINAIS
}

Conforme demonstrado, é preciso ter cuidado ao se legislar sobre o direito do outro para que fatalidades não sejam produzidas e desvantagens sejam geradas.

\footnotetext{
${ }^{2}$ Conforme definição da Organização Mundial da Saúde - OMS
} 
A cada ano que passa a população idosa brasileira aumenta, e sem dúvida, é preciso que essa parcela seja de fato protegida, com seus direitos, oportunidades e facilidades asseguradas.

De fato, existem idosos que são afetados pela senilidade patológica e que têm o discernimento reduzido, sendo preciso, dessa maneira, que o Estado atente para que a referida patologia não lhe traga problemas. Porém, não se deve generalizar, cada caso é um caso e tanto os jovens como os idosos podem ser vítimas de injustiças.

Quanto ao casamento, resta claro a inconstitucionalidade da imposição da lei em definir a idade e o regime de comunhão a ser adotado pelos nubentes e nenhuma justificativa é plausível para o assunto. Qualquer cidadão é vítima de preconceito quando sua liberdade de escolha, sua capacidade de discernimento e participação social e sua dignidade são limitadas e desrespeitadas.

Portanto, conclui-se que uma mudança no texto legal acerca da tal imposição é necessária para que de fato e em respeito ao próprio dispositivo do Estatuto do Idoso, ele possa gozar de todos os direitos fundamentais inerentes à pessoa humana.

\section{REFERÊNCIAS}

AMARAL, Francisco. Direito Civil: Introdução. 5a edição. Rio de Janeiro: Renovar, 2003.

ALVES, Jones Figuerêdo. As uniões septuagenárias e a separação absoluta de bens por pacto antenupcial com superação da Súmula 377 do STF. Disponível em:

http://www.ibdfam.org.br/artigos/1127>. Acesso em 16 arb. 2020.

BRASIL. Constituição (1988). Constituição da República Federativa do Brasil. 17.ed. São Paulo: Atlas, 2001.

BRASIL. Lei 10.741 de 01 de outubro de 2003. Dispõe sobre o Estatuto do idoso e dá outras providências. Diário Oficial da União, Brasília, 01 de outubro de 2003. Disponível em: < http://www.planalto.gov.br/ccivil_03/leis/2003/110.741.htm>. Acesso em 17 fev. 2020.

BRASIL. Lei 12.344 de 09 de dezembro de 2010. Altera a redação do inciso II do art. 1.641 da Lei no 10.406, de 10 de janeiro de 2002 (Código Civil), para aumentar para 70 (setenta) anos a idade a partir da qual se torna obrigatório o regime da separação de bens no casamento. Diário Oficial da União, Brasília, 9 dezembro 2010. Disponível em: <

http://www.planalto.gov.br/ccivil_03/_Ato2007-2010/>. Acesso em: 17 fev. 2020.

BRASIL. Portaria nº 2.528 de 19 de outubro de 2006. Aprova a Política Nacional de Saúde da Pessoa Idosa. Diário Oficial da União, Brasília, 19 de outubro de 2006. Disponível em: < http://bvsms.saude.gov.br/bvs/saudelegis/gm/2006/prt2528_19_10_2006.html >. Acesso em 16 abr. 2020.

BRASIL. Código civil, 2002. Código civil. 53.ed. São Paulo: Saraiva; 2002.

CARVALHO, João Andrades. Regime de bens. Rio de Janeiro: AIDE, 1996.

CHAUÍ, Marilena. Introdução à História da Filosofia. V.I. Dos pré-socráticos a Aristóteles. $2^{\mathrm{a} e d . ~ S a ̃ o ~ P a u l o: ~ C o m p a n h i a ~ d a s ~ L e t r a s, ~} 2002$.

CRETELLA JÚNIOR, José. Curso de direito romano. 7. ed. Rio de Janeiro: Forense, 1980. 
DINIZ, Fernanda Paula. Direitos dos idosos na perspectiva civil-constitucional, Arraes, 2011.

DINIZ, Maria Helena. Curso de Direito Civil Brasileiro. São Paulo: Saraiva, 2015.

DIAS, Maria Berenice. Manual de Direito das Famílias. São Paulo: Editora Revista dos Tribunais, 2015.

FERRIANI, Adriano. A obrigação de casar no regime da separação de bens por causa da idade. 2012. Disponível em: http://www.migalhas.com.br/Civilizalhas/94,MI152653,51045A+obrigacao+de+casar+no+regime+da+separacao+de+bens+por+causa+da+idade. Acesso em: fev. 2019.

FIÚZA. Cézar. Direito civil: curso completo. Belo Horizonte, Del Rey, 2004.

IBGE - INSTITUTO BRASILEIRO DE GEOGRAFIA E ESTATÍSTICA. Projeção da população do Brasil e das unidades de federação. Disponível em:

https://www.ibge.gov.br/apps/populacao/projecao/. Acesso em jan. 2020.

JUNIOR, Pedro Lino de Carvalho. O idoso e o direito de família. 2003. Disponível em: http://direitodoidoso.braslink.com/01/artigo007.html. Acesso em: 22 de fevereiro de 2019.

LUCAS, Mariana Andrade; OLIVEIRA, Valéria Edith Carvalho de. LJ 0135 - A inconstitucionalidade do regime de separação obrigatória de bens aos maiores de 70 anos. Letras jurídicas [online]. CENTRO UNIVERSITÁRIO NEWTON PAIVA - ISSN 2358-2154. Belo Horizonte, v.1, n.1, maio de 2014.

MORAES, Maria Celina Bodin. Princípios do direito contemporâneo. Renovar, 2006.

OLIVEIRA, Érika Arantes de; PASIAN, Sonia Regina e JACQUEMIN, André. A vivência afetiva em idosos. Psicol. cienc. prof. [online]. 2001, vol.21, n.1, pp. 68-83. ISSN 1414-9893.

ORGANIZAÇÃO MUNDIAL DA SAÚDE. Envelhecimento ativo: uma política de saúde. Brasília: Organização Pan-Americana da Saúde; 2005. Disponível em:

https://bibliotecadigital.mdh.gov.br/jspui/bitstream/192/401/1/WORLD_envelhecimento_200 5.pdf. Acesso em abr. 2020.

PEREIRA, Caio Mario da Silva. Instituições de Direito Civil. vol. V, Forense, 1994.

PEREIRA, Caio Mario da Silva. Instituições de Direito Civil. Rio de janeiro: Forense, 2016.

SENADO FEDERAL. Projeto de Lei do Senado nº 760, de 2015. Disponível em: https://www25.senado.leg.br/web/atividade/materias/-/materia/124248. Acesso em jan. 2020.

ROLLA, E. - apud: Gavião, A.C. (1995) Os efeitos da psicoterapia sobre alguns aspectos da personalidade de idosos. Exame Geral de Qualificação. Universidade de São Paulo, São Paulo, 1991. 
VELOSO, Zeno. As controvérsias da separação obrigatória de bens. Disponível em: http://www.ibdfam.org.br/noticias/6356/As+controv\%C3\%A9rsias+da+separa\%C3\%A7\%C3 $\%$ A3o+obrigat\%C3\%B3ria+de+bens. Acesso em 16 abr. 2020. 